\title{
Redes sociais dos profissionais da estratégia saúde da família no cuidado ao hipertenso
}

\author{
I ${ }^{1}$ Ana Zaira Silva, ${ }^{2}$ Maria Rocineide Ferreira Silva, ${ }^{3}$ Ana Larissa Gomes Machado, \\ ${ }^{4}$ Helena Maria Scherlowski David, ${ }^{5}$ Ligia Sansigolo Kerr, ${ }^{6}$ Lucilane Maria Sales da Silva I
}

Resumo: O estudo objetivou mapear as redes sociais dos profissionais da Estratégia Saúde da Família (ESF) a partir do cuidado ao hipertenso. Desenvolveu-se pesquisa quantitativa sob os referenciais da Análise de Redes Sociais, entre maio e julho de 2016, em Picos-PI. Os dados foram coletados através de entrevista semi-estruturada e a análise deu-se com o auxílio do software Ucinet e sua extensão de representação gráfica NetDraw. Os participantes foram profissionais de três equipes da ESF - médico, enfermeira, técnico de enfermagem e agente comunitário de saúde. A rede analisada foi composta por um total de 22 atores. Na dinâmica reticular, os atores com maior grau de centralidade foram o cardiologista, a enfermeira e o nutricionista. O coordenador da Atenção Básica também apresentou relevante grau de centralidade. A organizaçáo da rede e a dinâmica das relaçóes sociais refletem o modo como ocorre o cuidado, e conhecer a rede formada pelos profissionais da ESF na atenção ao hipertenso evidencia aspectos relacionados aos modos de produção do cuidado, decisivos para a promoção e manutenção da saúde dos usuários hipertensos.

> Palavras-chave: redes sociais; hipertensão; atenção primária à saúde.

\author{
1 Universidade Federal do Ceará. \\ Fortaleza-CE, Brasil (anazaira18@ \\ hotmail.com). \\ ORCID: 0000-0002-7016-9894 \\ 2 Universidade Estadual do \\ Ceará. Fortaleza-CE, Brasil \\ (rocineideferreira@gmail.com). \\ ORCID: 0000-0002-6086-6901 \\ ${ }^{3}$ Universidade Federal do Piauí. \\ Picos-PI, Brasil (analarissa2001@ \\ yahoo.com.br). \\ ORCID: 0000-0002-7937-6996 \\ ${ }^{4}$ Universidade do Estado do Rio \\ de Janeiro. Rio de Janeiro-RJ, Brasil \\ (helenalealdavid@gmail.com). \\ ORCID: 0000-0001-8002-6830 \\ ${ }^{5}$ Universidade Federal do Ceará. \\ Fortaleza-CE, Brasil (ligiakerr@ \\ gmail.com). \\ ORCID: 0000-0003-4941-408X \\ ${ }^{6}$ Universidade Estadual do \\ Ceará. Fortaleza-CE, Brasil \\ (lucilanemaria@yahoo.com.br). \\ ORCID: 0000-0002-3850-8753
}

Recebido em: 12/11/2019 Aprovado em: 21/04/2020 Revisado em: 05/10/2021 


\section{Introdução}

Entre as mais importantes doenças crônicas não transmissíveis (DCNT) na contemporaneidade, pode-se destacar a Hipertensão Arterial Sistêmica (HAS) por sua incidência e prevalência nas populaçóes (VIGITEL, 2017). Definida como uma condiçấo clínica multifatorial caracterizada por níveis elevados e sustentados da pressão arterial (PA), a HAS associa-se frequentemente às alteraçóes funcionais e estruturais dos órgãos-alvo como coraçáo, encéfalo, rins e vasos sanguíneos. $\mathrm{O}$ inadequado controle da PA tem ligação direta com eventos graves capazes de reduzir a longevidade e a qualidade de vida das pessoas, dentre os quais: acidente vascular encefálico (AVE), infarto agudo do miocárdio (IAM), insuficiência cardíaca (IC) e doença renal crônica (DRC) (MALACHIAS et al., 2016).

Pesquisas revelam que esta doença é responsável por no mínimo, 40\% dos óbitos causados pelo acidente vascular cerebral, $25 \%$ das mortes por doença arterial coronariana e, quando associada ao diabetes mellitus, contribui com 50\% dos casos de insuficiência renal terminal, dados que confirmam a necessidade de acompanhamento e cuidados contínuos junto aos usuários que apresentam esse agravo à saúde (BRASIL, 2013; PAZ et al., 2011).

Em cenário nacional, pesquisas estimam que a prevalência da HAS equivale a 35,8\% em todo o país (CHOR et al., 2015). No que diz respeito às regióes, a prevalência varia entre $7,2 \%$ a $40,3 \%$ no Nordeste; $5,04 \%$ a $37,9 \%$ no Sudeste; $1,28 \%$ a $27,1 \%$ no Sul; e 6,3\% a 16,75\% no Centro-Oeste (CAMARGO; ANJOS; AMARAL, 2013). Com efeito, o processo de trabalho e o modo de organização dos profissionais da saúde, especialmente no cenário da Estratégia Saúde da Família (ESF), constituem-se como elementos primordiais no estabelecimento de planos e ações coletivas e no desenvolvimento do cuidado da equipe multiprofissional junto aos usuários hipertensos (FERREIRA; PÉRICO; DIAS, 2018).

Compreende-se que a produção do cuidado se dá por meio de relações em redes, formadas pelos profissionais atuantes na ESF, nas quais os indivíduos se conectam, trocam informaçôes, recursos materiais e efetivam o cuidado de maneira coletiva. Os diferentes tipos de relações entre os profissionais dão-se de maneira direta ou indireta, de modo formal ou não, e somados a interesses individuais são cruciais ao desenvolvimento das atividades em equipe e podem ser compreendidos sob o prisma da análise das redes sociais (ARS), as quais representam um constructo 
teórico-metodológico de configuraçấo das relaçôes de atores no espaço social, ressaltando os fluxos de informação e os desenhos das suas açóes comunicativas (FIALHO, 2015; MARTELETO, 2001).

O termo redes sociais remete a uma multiplicidade de sentidos capazes de englobar contextos e açôes diversas, contemplando a pluralidade dos fenômenos sociais. Para se apropriar do conceito de redes sociais é imprescindível compreender as múltiplas correntes e linhas teóricas que perpassam a antropologia, psicologia, sociologia e matemática dos grafos, resultando na sua aplicabilidade enquanto (nova) forma de enxergar as relaçôes sociais, caracterizadas através das redes de comunicação e interação que envolvem uma linguagem simbólica, limites culturais e relaçôes de poder. Resultam, pois, em uma manifestação ampliada de conhecer, pensar e conceitualizar a realidade social, evidenciando-se a complexidade deste tema (FIALHO, 2015).

Neste particular, a abordagem das redes sociais no cuidado ao usuário hipertenso na atenção primária à saúde auxilia na identificação das relaçôes estabelecidas entre os diferentes profissionais da saúde e os usuários dos serviços, com base na necessidade de atenção contínua que este grupo requer e pelo número significativo de hipertensos atendidos na ESF.

Frente à busca constante por um modelo assistencial que contemple a acessibilidade, equidade, integralidade, humanizaçâo e que supere a histórica fragmentaçáo do ser cuidado, o estudo das redes sociais evidencia-se no cuidado ao hipertenso por revelar aspectos que implicam diretamente na atuação e nos resultados almejados pelos diversos atores sociais envolvidos (FONSECA et al., 2018; TOMAÉL; MARTELETO, 2013).

A ESF pode ser compreendida como um campo da saúde por representar um espaço social marcado pelo estabelecimento de relaçóes entre os indivíduos, grupos e estruturas sociais. A noção de campo tem por base um sistema de relações sociais (não relação entre agentes, mas entre posiçôes sociais que os agentes ocupam no campo), as quais muitas vezes resultam no estabelecimento de domínios e conflitos entre sujeitos que buscam manter alguma autonomia a partir de regras próprias e hierarquia social. Desse modo, as açóes dos profissionais atuantes nesse campo de atenção - ESF - estão associadas a esquemas individuais, socialmente constituídos de disposiçôes estruturadas e estruturantes, adquiridas através das vivências cotidianas 
que orientam o cuidado, sendo importantes para o entendimento das redes sociais que se estabelecem nesse cenário (BOURDIEU, 2009).

Assim, por saber que o cuidado dispensado aos hipertensos na ESF acontece a partir do envolvimento de uma equipe multiprofissional que precisa estabelecer laços contínuos a fim de garantir promoção da saúde adequada e minimização de agravos a saúde deste grupo, é que se compreende que uma rede social bem articulada pode ser decisiva para o sucesso de diversas atividades tais como melhora na adesão ao tratamento farmacológico, manutenção de uma alimentação saudável e prática de atividade física regular.

Por entender os esforços conjuntos de uma equipe multidisciplinar que estabelece laços constantes na busca de um cuidado integral à pessoa com hipertensão, objetivou-se mapear as redes sociais dos profissionais da ESF a partir do cuidado ao hipertenso, bem como identificar os atores mais significantes desse cenário, com base no grau de centralidade da rede formada.

\section{Métodos}

Os dados apresentados nesse artigo são resultados de uma dissertação de mestrado, com base em pesquisa descritiva, de natureza quantitativa, desenvolvida no período de maio a julho de 2016 em três unidades da ESF da zona urbana da cidade de Picos, no Estado do Piauí. A população constituiu-se pelos profissionais que compóem a equipe mínima da ESF (médico, enfermeira, técnico de enfermagem e agentes comunitários de saúde) de cada unidade, utilizando-se como critério de inclusão o período mínimo de um ano de atuação na ESF. A escolha das equipes foi realizada com base no maior número de hipertensos acompanhados em suas áreas de atuação.

Foram investigados inicialmente 12 profissionais e, a partir destes, foram identificados mais 10 atores como importantes na rede analisada, perfazendo um total de 22 profissionais pertencentes à rede investigada (rede total). Os profissionais foram convidados com antecedência a participar da pesquisa, respondendo a uma entrevista na própria Unidade de Saúde da Família (USF), em local reservado. A coleta dos dados ocorreu através de entrevista semiestruturada por meio da qual foi possível identificar os diversos atores envolvidos no cuidado direto ao hipertenso nesse nível de atenção, com base na questão norteadora: "Cite cinco pessoas com as quais você estabelece algum tipo de ligação frente ao cuidado do hipertenso". O intuito 
foi identificar, no primeiro momento, os indivíduos que se caracterizavam como os contatos, mediadores e/ou facilitadores do acesso e influenciadores do cuidado.

Efetuou-se a análise dos dados com o auxílio do software UCINET(C) e sua extensão de representação gráfica $\operatorname{NETDRAW(C),~os~quais~possibilitaram,~por~}$ meio de modelagem estatística e visualmente representativa, o mapeamento da rede social e as medidas de centralidade dos diversos atores.

O estudo foi submetido à apreciação do Comitê de Ética em Pesquisa da Universidade Estadual do Ceará (UECE) e aprovado conforme parecer no 1.506 .156$.

\section{Resultados e discussão}

A partir da análise dos elos constituídos pelos profissionais atuantes na ESF frente ao cuidado ao hipertenso, foi possível elaborar um desenho da rede formada pelos diversos atores envolvidos nesse contexto de cuidado e identificar aqueles com maior destaque nessa estrutura organizacional através da medida de centralidade de grau. Assim, elaborou-se a representação gráfica da rede social formada pelos profissionais pertencentes à equipe mínima da ESF e os demais atores com os quais se ligam a partir do cuidado direcionado aos usuários hipertensos (Figura 1).

Figura 1. Rede social formada para o cuidado do hipertenso no cenário da ESF.

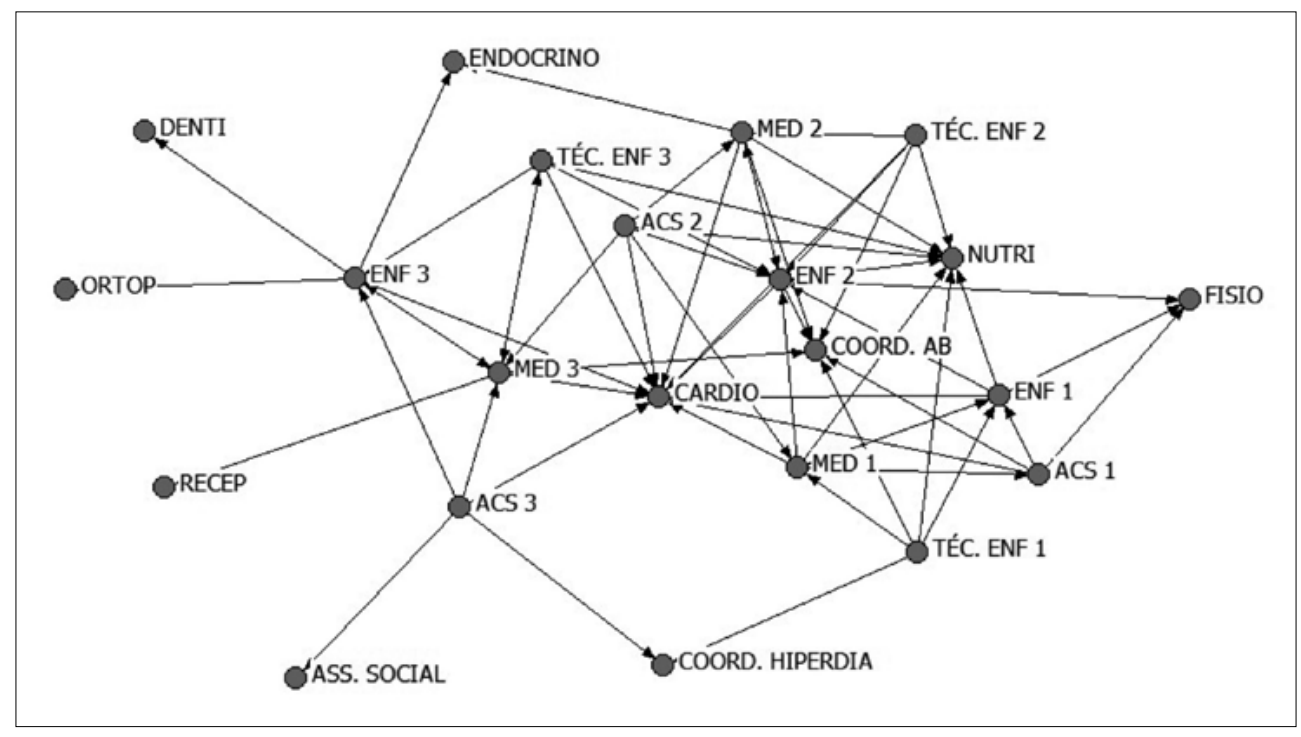

Fonte: Autores, 2016. 
A partir da figura 1, observam-se as diversas ligaçôes entre os profissionais, verificando-se no centro das açóes de cuidado os enfermeiros, médicos, nutricionista, coordenador da Atenção Básica (AB) e o cardiologista. A fim de possibilitar maior entendimento e clareza nos elos que se estabelecem entre esses profissionais, fez-se um desenho da rede agrupando os atores por categorias profissionais (Figura 2).

Figura 2. Rede social formada no cuidado ao hipertenso a partir das categorias profissionais.

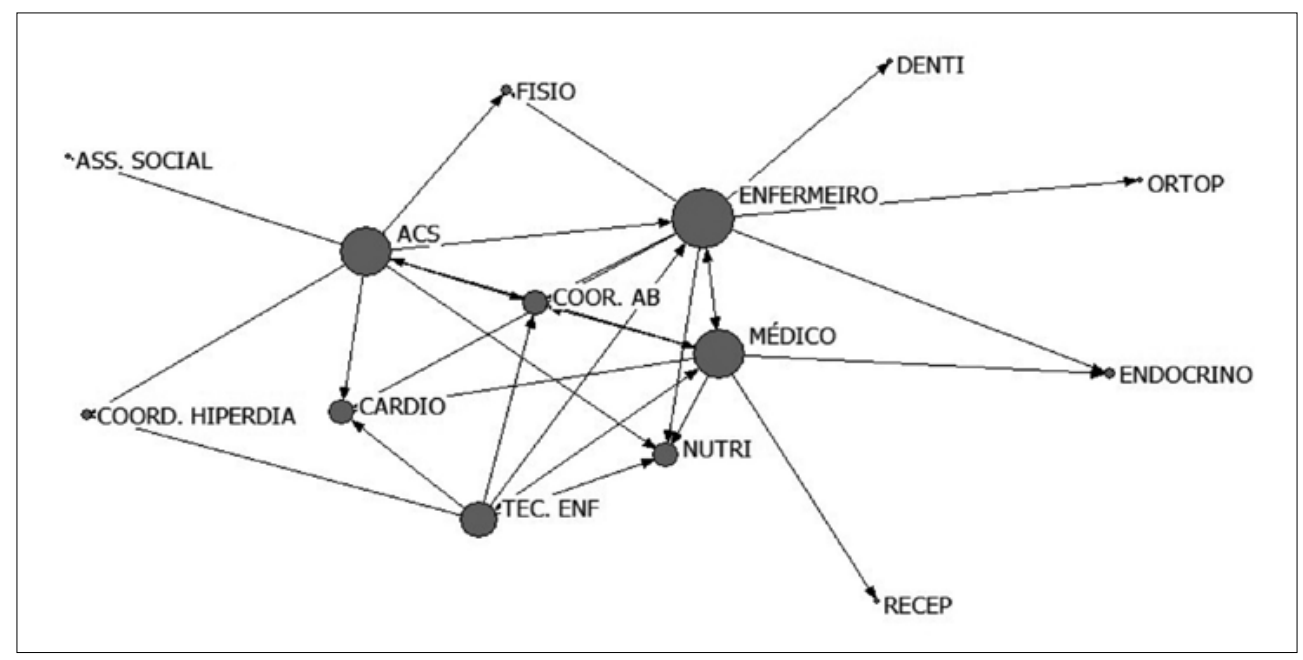

Fonte: Autores, 2016.

A figura 2 possibilita uma melhor visualização no que diz respeito à significância dos atores em termos de categoria profissional. Confirma-se a posição de centralidade dos profissionais médicos, enfermeiros, nutricionista, agentes comunitários de saúde, e coordenador da atenção básica.

As métricas de centralidade usadas refletem, na ARS, o grau de influências e prestígios dos atores, sendo o grau de entrada relativo ao quanto um determinado ator é buscado ou acionado. Grau de saída representa o quanto um ator é ativo na rede, procurando ou interagindo com outros atores (TOMAÉL; MARTELETO, 2006). O grau de entrada tende a ser o mais significante no contexto de análise das redes sociais no setor saúde, por indicar atores que contribuem efetivamente para a resolutividade das questóes de saúde. Estas métricas são mostradas no Quadro 1. 
Quadro 1. Medidas de centralidade de grau dos atores envolvidos no cuidado ao hipertenso na ESF.

\begin{tabular}{|c|c|c|c|}
\hline Atores & Grau de Saída & Grau de Entrada & Valor Relativo \\
\hline Cardio & 0.0 & 11.0 & 52.0 \\
\hline Nutri & 0.0 & 8.0 & 38.0 \\
\hline Coor. AB & 0.0 & 6.0 & 28.5 \\
\hline Enf 2 & 5.0 & 6.0 & 28.5 \\
\hline Méd 3 & 5.0 & 5.0 & 19.0 \\
\hline ACS 3 & 5.0 & 1.0 & 4.7 \\
\hline Téc. Enf. 2 & 5.0 & 1.0 & 4.7 \\
\hline Méd 2 & 0.0 & 3.0 & 14.2 \\
\hline Enf 1 & 5.0 & 3.0 & 14.2 \\
\hline Enf 3 & 5.0 & 3.0 & 14.2 \\
\hline Méd 1 & 5.0 & 3.0 & 14.2 \\
\hline Téc. Enf. 1 & 5.0 & 0 & 0.0 \\
\hline Téc. Enf. 3 & 5.0 & 0 & 0.0 \\
\hline ACS 1 & 5.0 & 0 & 0.0 \\
\hline ACS 2 & 5.0 & 0 & 0.0 \\
\hline Fisio & 0.0 & 3.0 & 14.2 \\
\hline Coor. Hiperdia & 0.0 & 2.0 & 9.5 \\
\hline Endocrino & 0.0 & 2.0 & 9.5. \\
\hline Ortop & 0.0 & 1.0 & 4.7 \\
\hline Ass. Social & 0.0 & 1.0 & 4.7 \\
\hline Denti & 0.0 & 1.0 & 4.7 \\
\hline Recep & 0.0 & 1.0 & 4.7 \\
\hline
\end{tabular}

Legenda: Cardio - Cardiologista; Nutri - Nutricionista; Coor. AB - Coordenador da Atenção Básica; Enf - Enfermeiro; Méd - Médico; ACS - Agente Comunitário de Saúde; Téc. Enf - Técnico de Enfermagem; Fisio - Fisioterapeuta; Coor. Hiperdia - Coordenador do Hiperdia; Endocrino Endocrinologista; Ortop - Ortopedista; Ass. Social - Assistente Social; Denti - Dentista; Recep Recepcionista. Fonte: Autores, 2016. 
Tem-se que os atores com maior grau de centralidade (grau de entrada) são respectivamente: cardiologista (11 graus), nutricionista (8 graus), enfermeira da equipe 2 (6 graus), coordenador da Atenção Básica (6 graus) e médico da equipe 3 (5 graus).

A formação de grupos é cada vez mais utilizada como estratégia para o desenvolvimento de açôes de saúde na ESF, sendo um requisito avaliado e incentivado pelos Ministérios da Saúde e Educação. Caracteriza-se grupo o conjunto restrito de pessoas que se ligam através de constantes de tempo e espaço e se articulam com objetivos e anseios partilhados, de modo explícito ou não, em busca da concretização de determinada tarefa e/ou finalidade (NAVARRO; GUIMARÁES; GARANHANI, 2013).Tomou-se nesta pesquisa o contexto da ESF e do cuidado ao hipertenso a partir de um grupo inserido em um campo.

O conceito de campo é descrito como um espaço em que acontecem as relaçôes entre os indivíduos, grupos e estruturas sociais. Ressalta-se que não são relações entre agentes, mas relaçóes entre posições que os agentes ocupam nesse campo, movidas pelas disputas que acontecem em seu interior, cujo movimento é constantemente o interesse em ser bem-sucedido nas relaçóes entre os seus componentes, no nível dos agentes ou das estruturas (BOURDIEU, 2007).

$\mathrm{Na}$ ESF a formação de grupos, traduzidos em grande escala por equipes de saúde, associa-se à realização de tarefas que envolvem diversas categorias profissionais que buscam coletivamente, o sucesso de suas ações. Considera-se o pressuposto empírico de que os profissionais desenvolvem interaçôes sociais com foco no cuidado ao usuário hipertenso, ao passo em que estão imersos em nós de redes complexas com o estabelecimento constante de elos - fortes ou fracos -, por meio de mediaçóes diversas que conferem sustentação à capacidade de resposta dos serviços de saúde diante dos agravos de saúde de determinada população (GOMIDE; SCHÜTZ, 2015).

Sabe-se que as relaçóes entre os diversos atores envolvidos em determinado processo de trabalho interferem no modo como estes lidam com suas responsabilidades, com os que estáo em seu entorno e com aqueles que estão acima ou abaixo do seu próprio nível hierárquico. Esses diferentes tipos de relaçóes entre pessoas, somados a interesses individuais, são cruciais ao desenvolvimento das atividades do grupo e, podem ser compreendidos através do prisma da ARS (TOMAÉL; MARTELETO, 2013). 
Com base nos achados, pode-se dizer que os atores com maior quantidade de ligaçóes têm uma posição mais vantajosa na rede, pelo fato de dispor de variadas alternativas para alcançar objetivos e superar necessidades e por isso são menos dependentes dos demais. Quando os atores, a exemplo dos médicos e enfermeiras, recebem muitas entradas, ou seja, são muito referenciados, eles estão mais propensos a ganhar destaque no cenário em que estão inseridos, já que os demais buscam estabelecer vínculo com estes. Assim, é cabível ressaltar que a categoria médica, representada pelos médicos da ESF e pelo cardiologista (atuante na atenção secundária), tem papel relevante no cenário de cuidado do hipertenso na rede desvendada, apontando a linha biomédica e hospitalocêntrica que permeia o cuidado no cenário da Atenção Básica. Uma vez que os médicos ocupam o centro da rede, entende-se que há uma valorização do cuidado baseado em tratamentos farmacológicos e açóes curativistas, que podem ameaçar o desenvolvimento das práticas de promoção e educação em saúde desenvolvidas pelos demais profissionais, a exemplo dos enfermeiros. Tais aspectos ratificam os achados de pesquisas que identificam a dependência que as demais categorias profissionais, no setor saúde, ainda preservam na atualidade frente à categoria médica, mesmo com todos os avanços conquistados, em termos tecnológicos e científicos (KANNO; BELLODI; TESS, 2012; LOPES; MARCON, 2012).

Neste contexto, conhecer a rede de relaçôes que se estabelecem a partir do cuidado ao hipertenso é imprescindível para a compreensão do desenvolvimento de açôes efetivas pelos profissionais da ESF, a partir da compreensão das disputas por posiçóes e visibilidade que acontecem entre os atores sociais, as quais se camuflam e afetam o desenvolvimento do cuidado a este público.

Um estudo desenvolvido no interior de Sáo Paulo, no cenário da ESF, mostrou que a categoria médica continua exercendo forte influência sobre os demais profissionais e consequentemente sobre a saúde das populaçóes em decorrência de vários fatores, dentre eles o diagnóstico de doenças e, o histórico poder da prescrição de medicamentos que limita as açôes dos demais integrantes da equipe. Nas relaçóes que se estabelecem entre médicos e demais profissionais, dentre eles o enfermeiro, encontra-se um vínculo que muitas vezes reflete na disputa de poder e na hierarquização de saberes inerentes à cada profissão, fato que pode constituir-se em um desafio frente ao cuidado do hipertenso por levar ao desgaste das relaçóes e fragilizar o processo de cuidado dos indivíduos e coletividades (LOPES; MARCON, 
2012). Ao desvendar as relações que se estabelecem entre os profissionais de saúde, é possível verificar a posição de vantagem/centralidade de cada um, bem como o distanciamento/descentralização que determinam muitas vezes as dificuldades de comunicação entre a equipe refletindo na fragmentação da atenção, e assim faz-se necessário desenvolver estratégias para o trabalho integral em equipe.

Nesse sentido, é possível explicar os elos construídos na rede de cuidados ao hipertenso, a partir do conceito de poder simbólico, que algumas categorias exercem sobre as outras como um poder invisível e dissimulado, que constrói a realidade a partir da subordinação dos agentes (NAVARRO; GUIMARÁES; GARANHANI, 2013). Para que o poder simbólico seja exercido é necessário que haja a cumplicidade daqueles que se submetem, com a consciência ou não dos que a ele estão sujeitos ou mesmo que o realizam. É um poder que constrói a crença da realidade, criando uma nova visão de mundo e por meio de estratégias de dominação organizadas e esquematizadas, sendo desnecessário o uso da força e assim torna perceptível o discurso dominante, interagindo, com a proposta de tornar oficial o pensamento e as demandas de um grupo ou dos agentes dominantes, que detêm o saber, a cultura e o capital (BOURDIEU, 2007).

Outra categoria profissional que se evidenciou nesse cenário de cuidado foi a enfermagem, sendo esta uma das profissóes mais mobilizadas para o gerenciamento das USF, cabendo a ela o compromisso, dentre outros encargos, de incentivar a participação dos demais membros da equipe na organização e produção de serviços de saúde que atendam às reais necessidades dos usuários. Os enfermeiros encontram na ESF um campo propício ao desenvolvimento de um trabalho pautado na prevenção de agravos, promoção e reabilitação da saúde dos indivíduos e comunidades, a partir do momento em que dedicam grande parte de suas atividades ao contato direto com os indivíduos e comunidades, estabelecendo e fortalecendo os vínculos. $\mathrm{O}$ fato de conhecer de perto os usuários, o contexto no qual estão inseridos, bem como suas peculiaridades, anseios e os círculos sociais nos quais estão envolvidos, talvez seja um o principal motivo capaz de garantir seu papel de destaque dentro da rede social (AZEVEDO et al., 2013; FERNANDES et al., 2012).

Entretanto, o trabalho da enfermagem neste campo de atuação requer maior reconhecimento que se traduza na valorização econômica desta prática e na agregação de maior capital social, sendo este definido, como um agregado de recursos atuais ou potenciais, vinculados à posse de uma rede duradoura de relaçóes de familiaridade 
ou reconhecimento mais ou menos institucionalizadas (BOURDIEU, 1983). Neste sentido, o capital social que um dado agente possui depende da extensão da rede de relaçôes por ele mobilizada e do reconhecimento deste pelos demais atores da rede.

Neste particular, faz-se oportuno destacar que a enfermagem é essencialmente uma prática de relaçôes, além de ciência do cuidado e da saúde, que busca através da sua evolução uma mudança paradigmática expressa através da necessidade de um agir eminentemente interdisciplinar e pautado na produção de saberes científicos e tecnológicos. Através da gestão e gerenciamento das ações e serviços de saúde, o enfermeiro destaca-se no cenário do cuidado e é, repetidamente, identificado como ator indispensável nesse contexto de atuação (BOURDIEU, 1983; LANZONI; MEIRELLES, 2013).

Outra questão a ser relatada é o fato de o nutricionista ter ganhado destaque na rede social identificada, ressaltando a ideia de que está havendo uma mudança de paradigma no cenário da $\mathrm{AB}$. De modo lento e progressivo, os profissionais estão incorporando a ideia de promoção da saúde através do trabalho interdisciplinar, com vistas a minimizar ou mesmo neutralizar os agravantes de saúde de determinada população, a partir do desenvolvimento de açôes de cunho preventivo e emancipatório, especialmente através da educação em saúde onde tanto o nutricionista quanto os enfermeiros se destacam como indispensáveis para a concretização de tais atividades (ACIOLI et al., 2014).

Outro profissional que merece referência é o agente comunitário de saúde que embora não tenha apresentado grau de entrada elevado, destaca-se como ator capaz de interligar e/ou acionar vários outros profissionais da equipe ou fora dela, induzindo ou possibilitando a sua entrada na rede assistencial do hipertenso. Acredita-se que o ACS por ter como uma das principais características do seu trabalho o contato direto com os usuários e a realidade na qual estáo inseridos, identifica através das atividades desenvolvidas na própria ESF ou por meio das visitas domiciliares as necessidades de cada sujeito e, a partir daí, estabelecer ligações com outros profissionais com base na ampliação de visôes e maior flexibilidade no estabelecimento das relaçóes, buscando satisfazer as carências dos pacientes (FIALHO, 2015).

Desse modo, entende-se que a ESF propóe na sua essência o desenvolvimento de práticas de saúde que englobam além de conteúdos técnicos e científicos, os relacionamentos (formais ou não), ainda tão pouco relatados e discutidos na literatura atual. A própria natureza da ESF inclui a proposta da criação de vínculo 
contínuo, entre a equipe multiprofissional, destacando desde os ACS, técnicos de enfermagem, nutricionistas, enfermeiros, médicos, e demais profissionais, e destes com os usuários, com foco na ideia de se trabalhar geograficamente mais próximo das comunidades a partir da elaboração de planejamentos que promovam a saúde das pessoas e que envolvam a participação interdisciplinar das mais diversas categorias profissionais (KANNO; BELLODI; TESS, 2012).

Muitas são as potencialidades do processo de trabalho da equipe atuante na ESF sob a ótica das redes sociais, dentre elas estão o caráter multiprofissional e interdisciplinare o contato direto e prolongado com a populaçáo que se destacam como aliados no enfrentamento e controle da hipertensão. Como fragilidade desta rede, ressalta-se o caráter farmacológico e hospitalocêntrico ainda evidenciado na centralidade das relações sociais estabelecidas com os profissionais médicos (especialistas), implicando em distanciamento e/ou fragmentação de elos entre os demais profissionais de saúde envolvidos no cuidado e os usuários hipertensos na ESF.

\section{Conclusão}

$\mathrm{O}$ estudo analisou as redes sociais formadas a partir do cuidado ao hipertenso no cenário da atenção primária à saúde, as quais evidenciaram o médico especialista no centro das relaçôes e um cuidado mais voltado aos aspectos farmacológicos e à fragmentação das açôes profissionais.

Há muitas dificuldades no processo de cuidado do hipertenso no cenário avaliado, desde a escassez de recursos humanos e materiais, condiçôes estruturais desfavoráveis, até a fragilidade das relaçôes entre as categorias profissionais. Assim, o conhecimento das redes sociais formadas no cuidado ao hipertenso torna-se essencial para fortalecer os elos entre profissionais da equipe de saúde e usuários, considerando a importância do saber de cada profissional para promoçáo do cuidado integral.

\section{Referências}

ACIOLI, S. et al. Práticas de cuidado: o papel do enfermeiro na atenção básica. Rev. Enferm. UERJ, v. 22, n. 5, p. 637-642, 2014. Disponível em: <http://www.facenf.uerj.br/v22n5/ v22n5a09.pdf>. Acesso em: 12 dez. 2017.

AZEVEDO, I. C. et al. A teoria clássica da administraçáo no âmbito da enfermagem e da atenção básica. Rev. APS, v. 16, n. 3, p. 338-343, 2013. Disponível em: <https://periodicos.ufjf. br/index.php/aps/article/view/15223 >. Acesso em: 10 out. 2017. 
BOURDIEU, P. Questões de sociologia. Rio de Janeiro: Editora Marco Zero Limitada, 1983.

BOURDIEU, P. O poder simbólico. 11 ed. Rio de Janeiro: Bertrand, 2007.

BOURDIEU, P. A economia das trocas simbólicas. 6 ed. São Paulo: Perspectiva, 2009.

BRASIL. Ministério da Saúde. Cadernos de atençâo básica: estratégias para o cuidado da pessoa com doença crônica - Hipertensão Arterial Sistêmica. 1 ed. Brasília: Ministério da Saúde, 2013. Disponível em: <http://ecos-redenutri.bvs.br/tiki-read_article.php?articleId=948>. Acesso em: 26 set. 2016.

BRASIL. Ministério da Saúde. Secretaria de Vigilância em Saúde. Departamento de Vigilância de Doenças e Agravos Não Transmissíveis e Promoção da Saúde. Vigitel Brasil 2017: vigilância de fatores de risco e proteção para doenças crônicas por inquérito telefônico: estimativas sobre frequências e distribuição sociodemográfica de fatores de risco e proteção para doenças crônicas nas capitais dos 26 estados brasileiros e Distrito Federal em 2017. Brasília: Ministério da Saúde; 2017 [intenet]. Disponível em: <http://bvsms.saude.gov.br/bvs/publicacoes/vigitel_brasil_2017_vigilancia_ fatores_risco_1ed_rev.pdf>. Acesso em: 15 jun. 2018.

CAMARGO, R. A. A.; ANJOS, F. R.; AMARAL, M. F. Estratégia saúde da família nas açóes primárias de saúde ao portador de hipertensão arterial sistêmica. Rev. Min. Enferm, v. 17, n. 4, p. 864-872, 2013. Disponível em: < http://www.reme.org.br/artigo/detalhes/892>. Acesso em: 15 jan. 2017.

FERNANDES, M. C. et al. Fatores intervenientes na gerência do cuidado do enfermeiro: estudo descritivo. Online Brazilian Journal of Nursing, v. 12, n. 2, p. 522-533, 2012. Disponível em: < http://www.objnursing.uff.br/index.php/nursing/article/viewFile/4081/pdf_1>. Acesso em: 09 mar. 2017.

FERREIRA, S. R. S.; PÉRICO, L. A. D.; DIAS, V. R. F. G. A complexidade do trabalho do enfermeiro na Atenção Primária à Saúde. Rev. Bras. Enferm, v. 71, n. Supl 1, p. 752757, 2018. Disponível em: <http://www.scielo.br/scielo.php?script=sci_arttext\&pid =S0034-71672018000700704>. Acesso em: 15 mar. 2017.

FIALHO, J. Pressupostos para a construção de uma sociologia das redes sociais. Revista de Letras da Universidade do Porto, v. 29, p. 59-79, 2015. Disponível em: <https://ler.letras.up.pt/ uploads/ficheiros/13338.pdf>. Acesso em: 10 abr. 2018.

FONSECA, J. DOS S. A. et al. Redes sociais, acesso e regulação dos serviços de saúde em um município de pequeno porte do Rio de Janeiro, Brasil. Ciência \& Saúde Coletiva, v. 23, n. 10, p. 3211-3222, 2018. Disponível em: <https:/www.scielosp.org/article/ssm/content/raw/?resource_ ssm_path=/media/assets/csc/v23n10/1413-8123-csc-23-10-3211.pdf>. Acesso em: 14 jun. 2019. GOMIDE, M.; SCHÜTZ, G. E. Análise de redes sociais e práticas avaliativas: desafios à vista. Physis Revista de Saúde Coletiva, v. 25, n. 3, p. 819-842, 2015. Disponível em: <http://www.scielo. br/scielo.php?script=sci_arttext\&pid=S0103-73312015000300819>. Acesso em: 10 out. 2019. 
KANNO, N. D. P.; BELLODI, P. L.; TESS, B. H. Profissionais da Estratégia Saúde da Família diante de Demandas Médico-Sociais: dificuldades e estratégias de enfrentamento. Saúde, Sociedade, v. 21, n. 4, p. 884-894, 2012. Disponível em: <http://www.scielo.br/scielo.php?pid= S010412902012000400008\&script=sci_abstract\&tlng=pt>. Acesso em: 23 jan. 2018.

LANZONI, G. M. DE M.; MEIRELLES, B. H. S. Liderança do enfermeiro: elemento interveniente na rede de relaçóes do agente comunitário de saúde. Rev. Bras. Enferm, v. 66, n. 4, p. 557-563, 2013. Disponível em: <http://www.scielo.br/scielo.php?script=sci_arttext\&pid $=$ S0034-71672013000400014>. Acesso em: 17 mai. 2018.

LOPES, M. C. DE L.; MARCON, S. S. Assistência à família na atenção básica: facilidades e dificuldades enfrentadas pelos profissionais de saúde. Acta Scientriarum. Health Sciences, v. 34, n. 1, p. 85-93, 2012. Disponível em: <http://docs.bvsalud.org/biblioref/2016/08/1311/762461172-1-pb.pdf>. Acesso em: 10 jun. 2017.

MALACHIAS, M. V. B. et al. 7a Diretriz Brasileira de Hipertensão Arterial. Arq. Bras. Cardiol., v. 107, n. 3, p. 1-83, 2016. Disponível em: <http://publicacoes.cardiol.br/2014/ diretrizes/2016/05_HIPERTENSAO_ARTERIAL.pdf>. Acesso em: 10 dez. 2016.

MARTELETO, R. M. Análise de redes sociais - aplicação nos estudos de transferência da informação. Ciência da Informação, v. 30, n. 1, p. 71-81, 2001. Disponível em: <http://www. scielo.br/pdf/ci/v30n1/a09v30n1.pdf>. Acesso em: 28 jun. 2016.

NAVARRO, A. S. DE S.; GUIMARÃES, R. L. DE S.; GARANHANI, M. L. Trabalho em equipe: o significado atribuído por profissionais da estratégia de saúde da família. Ver. Min. Enferm, v. 17, n. 1, p. 61-68, 2013. Disponível em: <http://www.reme.org.br/artigo/ detalhes/579>. Acesso em: 10 mar. 2018.

PAZ, E. P. A. et al. Estilos de vida de pacientes hipertensos atendidos com a Estratégia de Saúde Familiar. Invest. Educ. Enferm, v. 29, n. 3, p. 467-476, 2011. Disponível em: <http://www. scielo.org.co/scielo.php?script=sci_abstract\&pid=S0120-53072011000300016>. Acesso em: 17 set. 2015.

TOMAÉL, M. I.; MARTELETO, R. M. Redes Sociais: posições dos atores no fluxo da informação. Rev. Elet. Bibliotecon, Ci. e Inf, n. esp., p. 75-91, 2006. Disponível em: <https:// periodicos.ufsc.br/index.php/eb/article/view/1518-2924.2006v11nesp1p75/387>. Acesso em: 10 set. 2015.

TOMAÉL, M. I.; MARTELETO, R. M. Redes sociais de dois modos: aspectos conceituais. TransInformação, v. 25, n. 3, p. 245-253, 2013. Disponível em: <http://www.scielo.br/scielo. php?pid=S010337862013000300007\&script=sci_abstract\&tlng=pt>. Acesso em: 03 mar. 2017. 


\section{Abstract}

\section{The social networks of the family bealth strategy professionals for the hypertensive patient care}

The scope of this study was mapping social networks used by professionals from the family health strategy aimed at offering care to hypertensive patients. It is a descriptive study using a quantitative research based on reference analysis of social networks developed between May and July of 2016, In Picos-PI. Data was collected with the help of Ucinet software and its Netdraw graphic representations. Participants were professionals from three family health strategy teams - doctor, nurse, nursing technician and health department community agent. The network analyzed was composed of a total of 22 actors. In reticular dynamics, the actors with the highest degree of centrality were the cardiologist, the nurse and the nutritionist. The primary care coordinator also presented a relevant degree of centrality. The organization of the network and the dynamics of social relations reflect the way care occurs, and knowing the social network formed by professionals of the family health strategy in hypertensive care highlights aspects related to the modes of care production, which is decisive for the promotion and maintenance of the health of users with hypertension.

> Keywords: Social networking; Hypertension; Primary health care. 